\title{
The Inter-play of the Opto-Electrical Properties of Cuprite and Tenorite Semiconductors for Solar Cell Application
}

\author{
Agumba Onyango John ${ }^{1, ~ *, ~ A d e m ~ A b i b o ~ J a c k ² ~}$ \\ ${ }^{1}$ Department of Mathematics and Physics, Pwani University, Kilifi, Kenya \\ ${ }^{2}$ Department of Biological and Physical Sciences, Jaramogi Oginga Odinga University of Science and Technology, Bondo, Kenya
}

Email address:

agumba.john@gmail.com (A. O.John)

*Corresponding author

\section{To cite this article:}

Agumba Onyango John, Adem Abibo Jack. The Inter-play of the Opto-Electrical Properties of Cuprite and Tenorite Semiconductors for Solar Cell Application. American Journal of Nano Research and Applications. Vol. 5, No. 6, 2017, pp. 81-86. doi: 10.11648/j.nano.20170506.11

Received: October 12, 2017; Accepted: October 23, 2017; Published: December 7, 2017

\begin{abstract}
The electrical and optical properties of cuprous oxide $\left(\mathrm{Cu}_{2} \mathrm{O}\right)$ thin films prepared by D.C. reactive magnetron sputtering technique have been systematically studied. The influence of the film deposition conditions on the opto-electrical properties has been investigated and has helped to solve the puzzles of difficulties associated with preparation of high quality $\mathrm{Cu}_{2} \mathrm{O}$ films. This is because there is usually co-deposition of phases of $\mathrm{Cu}, \mathrm{Cu}_{2} \mathrm{O}$ and $\mathrm{CuO}$ during the preparation of $\mathrm{Cu}_{2} \mathrm{O}$ films. From this study, the films deposited at low substrate temperature were found to be less crystalline as compared to those deposited at high substrate temperature. This was corroborated by the drop in the sheet resistivity from $\sim 55.08 \Omega \mathrm{cm}$ to $\sim 29.66 \Omega \mathrm{cm}$ and the band gap from $\sim 2.36 \mathrm{eV}$ to $\sim 1.63 \mathrm{eV}$ for films prepared at substrate temperatures of $23^{\circ} \mathrm{C}$ and $170^{\circ} \mathrm{C}$ respectively. Annealing was also found to improve the film crystallinity.
\end{abstract}

Keywords: Cuprite, Tenorite, Optical, Electrical, Sputtering, Annealing

\section{Introduction}

Cuprous oxide $\left(\mathrm{Cu}_{2} \mathrm{O}\right)$ is a non-stoichiometric defect semiconductor that is highly desirable semi- conductor oxide for use in solar cell application. It is a direct band gap $\left(E_{g}=\right.$ 1.9-2.2eV) [1-2] and a high absorption coefficient semiconductor that absorbs visible light of wavelengths up to 650nm. [1-5]. In addition, $\mathrm{Cu}_{2} \mathrm{O}$ is preferred since it is nontoxic, cheap, easy to controllably deposit, have sufficient mobility and a relatively large minority carrier diffusion length [6-9]. Further, it has outstandingly large exciton binding energy of $\sim 140 \mathrm{meV}$ that has made it a target of current research [6-16]. Many techniques have been used in preparation of $\mathrm{Cu}_{2} \mathrm{O}$ thin films. These include Copper thermal oxidation [17, 18], chemical oxidation [19], sol-gel method [20], electro-deposition [21], and gas-phase deposition that includes radio frequency (rf) magnetron or reactive sputtering, vacuum evaporation, molecular beam epitaxy and laser ablation [22]. Among these techniques, sputtering is a versatile and low-cost technique for preparing $\mathrm{Cu}_{2} \mathrm{O}$ thin films [23]. In this study, due to its advantages such as proper control on the film chemical composition, high deposition rate and low substrate heating during film deposition $[11,13,16]$, DC reactive magnetron sputtering technique has been adopted. Properties of $\mathrm{p}-\mathrm{Cu}_{2} \mathrm{O}$ strongly depend on the details of the oxidation process. It has been suggested that during oxidation, cuprous oxide $\left(\mathrm{Cu}_{2} \mathrm{O}\right)$ is formed first and after a sufficient long oxidation time, tenorite $(\mathrm{CuO})$ is formed [24]. The oxidation process includes two steps represented by the chemical equations below.

$$
\begin{aligned}
& 4 \mathrm{Cu}+\mathrm{O}_{2} \rightarrow 2 \mathrm{CuO} \\
& 2 \mathrm{Cu}_{2} \mathrm{O}+\mathrm{O}_{2} \rightarrow 4 \mathrm{CuO}
\end{aligned}
$$

These two reactions can be evaluated thermodynamically using Gibbs free-energy equation below.

$$
\Delta G=\Delta H-T \Delta S
$$

where $\Delta G$ is the change in Gibbs free energy, $\Delta H$ is the change in enthalpy, $\mathrm{T}$ is the reaction temperature and $\Delta H$ is the change in entropy. The oxidation process for copper starts with formation of $\mathrm{Cu}_{2} \mathrm{O}$ first and then with gradual oxidization 
to $\mathrm{CuO}$, depending on the temperature and time allowed for the reaction.

\section{Experimental}

\subsection{Preparation of $\mathrm{Cu}_{2} \mathrm{O}$ Thin Films}

In this paper, glass substrates were used unless otherwise stated. The glass substrates were first cleaned in dilute chromic acid rinsed thoroughly with distilled water and ethanol. This was to remove any surface contaminants. The substrates were then allowed to dry completely. The $\mathrm{Cu}_{2} \mathrm{O}$ films were then deposited on the glass substrates by DC reactive magnetron sputtering technique using Edward's AUTO 306 vacuum coater. Before deposition, ultimate vacuum was created in the chamber by pumping it with diffusion pump and rotary pump combination until a base pressure of $2.5 \times 10^{-6}$ mbar was recorded by Pirani-Penning gauge combination. 99\% pure copper target was then pres-sputtered in pure argon atmosphere for ca. 15 minutes in order to remove oxide layers formed if any on the target with a shutter incorporated below the sputtering target to isolate the substrate during the pre-sputtering process. This step is usually essential in the reactive sputtering to obtain the films with reproducible Mechanical and opto-elecronic properties.

After the pre-sputtering process, oxygen gas was admitted in to the chamber until oxygen partial pressure of $2 \times 10^{-4} \mathrm{mbar}$ was achieved. Argon gas was then introduced so as to reach the required sputtering pressure of $1.9 \times 10^{-2}$ mbar. The flow rates of both argon and oxygen gases were controlled individually by tylan mass flow controllers operated by a computer running LabVIEW program. A continuously variable DC power supply of $750 \mathrm{~V}$ and $3 \mathrm{~A}$ was used to regulate the discharge current of $200 \mathrm{~mA}$. The full thin film preparation conditions adopted are shown in Table 1. The substrate shutter was then removed to allow deposition of the films on the glass substrates. In this process, the argon ions $\left(\mathrm{Ar}^{+}\right)$were accelerated towards a copper target dislodging copper atoms which then reacted with oxygen atoms forming thin films of $\mathrm{Cu}_{2} \mathrm{O}$ that was deposited on the glass substrates.

Table 1. Sputtering conditions during the $\mathrm{Cu}_{2} \mathrm{O}$ thin film deposition.

\begin{tabular}{ll}
\hline Sputtering Target & $\begin{array}{l}\text { Pure copper }(\mathbf{1 0 0 m m} \text { diameter and 3mm } \\
\text { thick and } \mathbf{9 9 . 9 9 \%} \text { pure })\end{array}$ \\
\hline Base pressure & $2.5 \times 10^{-6} \mathrm{mbar}$ \\
Oxygen partial pressure & $2.0 \times 10^{-4} \mathrm{mbar}$ \\
Target-substrate distance & $65 \mathrm{~mm}$ \\
Sputtering pressure & $1.9 \times 10^{-2} \mathrm{mbar}$ \\
Substrate temperature & $35^{\circ} \mathrm{C}, 50^{\circ} \mathrm{C}, 100^{\circ} \mathrm{C}, 170^{\circ} \mathrm{C}$ \\
Sputtering time & $15 \mathrm{~min}, 25 \mathrm{~min}, 40 \mathrm{~min}$ \\
Cathode current & $200 \mathrm{~mA}$ \\
\hline
\end{tabular}

The $\mathrm{Cu}_{2} \mathrm{O}$ films were deposited at a fixed oxygen partial pressure, sputtering power and sputtering pressure. However, substrate temperature and sputtering time were varied. One hour after completing the sputtering processes and power switched off, the deposited $\mathrm{Cu}_{2} \mathrm{O}$ thin film samples were removed from the chamber for characterization.

\subsection{Film Thickness Measurements}

For the thin film thickness measurements, the stylus-method profilometry was adopted. The method entailed measuring the mechanical movement of a diamond needle (stylus) as it was made to trace the topography of the film-substrate steps that were created during the films' formation by masking parts of the substrates with aluminum foil before the deposition process. To measure the thickness, thin films were placed on the profilometer device stage and then fine stylus dragged across the film surface. When the stylus encountered a step, signal variations (based on a differential capacitance or inductance technique) indicated the step height.

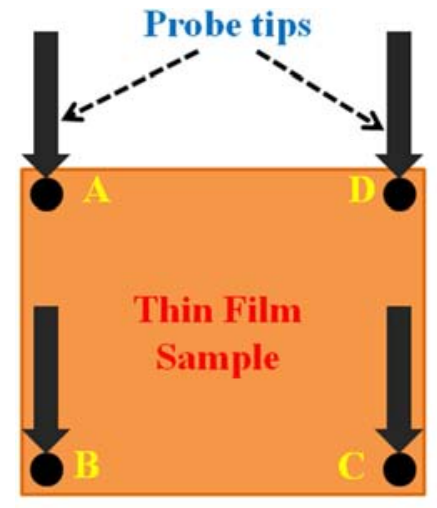

SourceMeter 2400

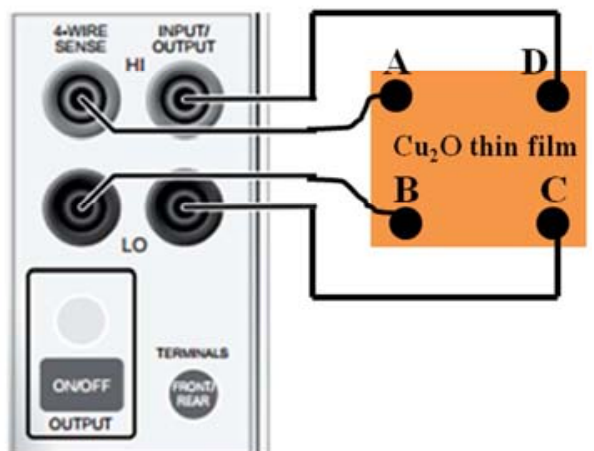

Figure 1. Probe tips on film sample surface with square geometry and connections to SMU 2400 Source Meter unit.

\subsection{The Optical Spectroscopy on $\mathrm{Cu}_{2} \mathrm{O}$ Thin Films}

The absorbance spectra were collected by 1800 Shimadzu photospectrometer and the optical band-gap determined based on UV-V is transmission in the $300-800 \mathrm{~nm}$ range. The slit size remained at $1 \mathrm{~nm}$ throughout the scans.

\subsection{The Electrical Characterization}

To perform sheet resistivity measurement, the Van der Pauw method with square symmetry was adopted. Small contacts were made and placed on the circumference of the sample as depicted in Figure 1. We ensured that samples had 
constant thickness with no isolated holes. Keithley Source Meter unit 2400 model was used to source current through two terminals and the voltage measured via the opposite terminals.

\subsection{The Structural Characterization of $\mathrm{Cu}_{2} \mathrm{O}$ Thin Films}

In order to get the structural order (the unit cell parameters) of $\mathrm{Cu}_{2} \mathrm{O}$ thin films, WAXS measurements were performed on the films using a modified Siemens D500 X-ray diffractometer with a conventional $\mathrm{CuK} \alpha \mathrm{X}$-ray source of wavelength $\lambda=0.1542 \mathrm{~nm}$ reflection mode. One sample was structurally characterized as deposited while other samples were annealed first in a Lindberg/Blue Tube Furnace TF55035A model before the WAXs measurements.

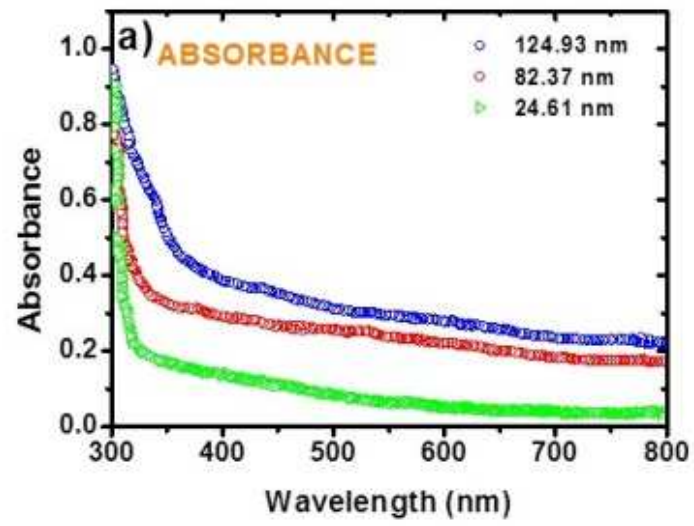

\section{Results and Discussion}

\subsection{Optical Spectroscopy on $\mathrm{Cu}_{2} \mathrm{O}$ Thin Films}

Figure 2 shows the absorbance (a) and transmittance (b) spectra of copper oxide thin films at three different film thicknesses. The as-deposited $\mathrm{Cu}_{2} \mathrm{O}$ films were found to have a very high optical absorption in the visible spectra. It was further found that all the films behaved as absorber materials at about $400-800 \mathrm{~nm}$ wavelength range. Also interesting to note was that the absorbance of each film decreased with increasing wavelength and with decreasing film layer thicknesses.

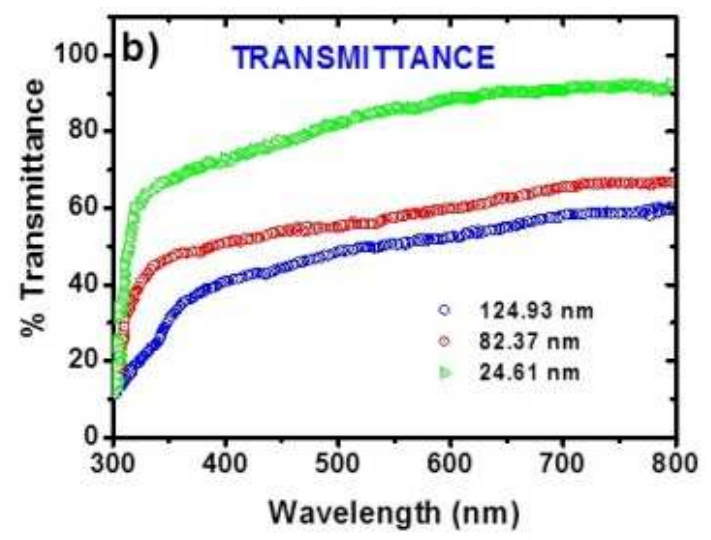

Figure 2. The absorbance (a) and transmittance spectra (b) of $\mathrm{Cu}_{2} \mathrm{O}$ thin films of different thicknesses.

\subsection{Optical Band Gap $\left(E_{g}\right)$ Measurement}

The optical absorption is dominated by the optical band gap $\left(E_{g}\right)$ of the semiconductor that is related to the optical absorption coefficient $(\alpha)$ and the incident photon energy hv by using Tauc equation below.

$$
\alpha h v=A\left(h v-E_{g}\right)^{n}
$$

In this equation, $\alpha$ is absorption coefficient, $\mathrm{A}$ is constant that is independent from $v$ and $n$ the exponent that depends on the kind of optical transition. This constant can be $1 / 2$ when the

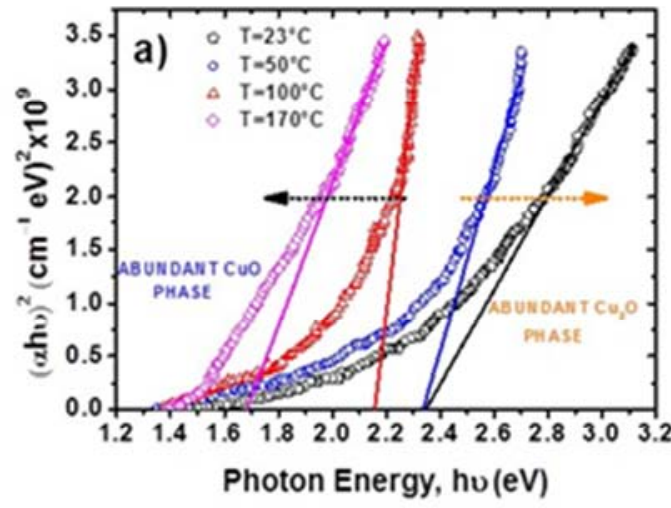

transition is direct-allowed and 2 when it is indirect- allowed. In this experiment, the value of $n$ was found to be $1 / 2$ (which corresponds to direct band to band transition) because that value of $n$ yields the best linear graph of $(\alpha h v)^{2}$ verses hv. The photon energy is given by hv [25-29]. The intersection of the straight line with the hv-axis determines the optical band gap energy $E_{g}$. The direct allowed energy band gap $\left(E_{g}\right)$ must be overcome for the electronic transition from the upper level of valence band and the lower level of conduction band. The substrate temperature highly affected the bandgap of the resulting film.

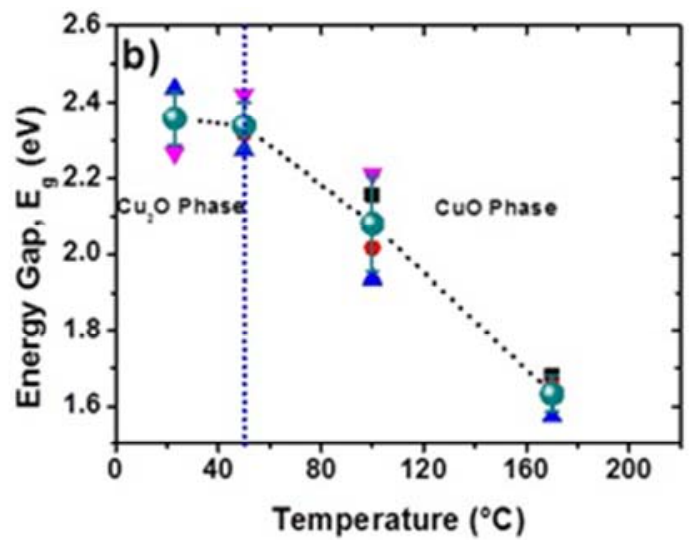

Figure 3. A graph of $(\alpha h v)^{2}$ versus photon energy, $h v$ for thin films prepared at different substrate temperatures (a) and optical bandgap, (E $\left.{ }_{g}\right)$ verses substrate temperatures $(b)$. 
Figure 3 (a) shows a graph of $(\alpha h v)^{2}$ versus photon energy, hv for thin films prepared at different substrate temperatures from $23^{\circ} \mathrm{C}$ and $170^{\circ} \mathrm{C}$ while Figure 3 (b) shows the variation of the optical bandgap, $\left(\mathrm{E}_{\mathrm{g}}\right)$ with the substrate temperatures during the film deposition. Both the films deposited at $23^{\circ} \mathrm{C}$ and $50^{\circ} \mathrm{C}$ had nearly the same optical band gap at $2.35 \mathrm{eV}$ showing that they possess similar cuprite structure with $\mathrm{Cu}_{2} \mathrm{O}$ phase being dominant. The oxidation temperature (substrate temperature) determined the composition of $\mathrm{Cu}_{2} \mathrm{O}$ and $\mathrm{CuO}$ phases. The conversion of $\mathrm{Cu}_{2} \mathrm{O}$ into $\mathrm{CuO}$ could result from the diffusion of oxygen into the films. We conclude that thin films comprising of more $\mathrm{Cu}_{2} \mathrm{O}$ composition with high bandgap were formed at low substrate temperature while more abundant $\mathrm{CuO}$ thin films of low bandgap were formed at high substrate temperature.

\subsection{Optical Band Gap $\left(E_{g}\right)$ Measurement}

The I-V measurements plot for cuprous oxide thin films of different thicknesses are shown in Figure 4. In this experiment, Platinum $(\mathrm{Pt})$ was used as the mental contacts in order to minimize the contact resistance and ensure ohmic contact. The $\mathrm{I}-\mathrm{V}$ measurements were performed using two probe method with applied voltage varying between -5 to $5 \mathrm{~V}$. During this measurement, it was ensured that the contacts of the probe head firmly touched the film surface to produce reliable and reproducible data. All the three films showed the Ohmic behavior with linear I-V curves as the current between two points was directly proportional to the applied voltage across the two points. The resistance of the films decreased with the film thickness as depicted in the graph suggesting more ordered microstructures forming in the thick films.

\subsection{Sheet Resistivity of Thin Film Sheets}

When only two probes are performed on a thin film surface, the sheet resistance is usually given by equation (5).

$$
R_{s}=\frac{\pi}{\ln (2)} f(Q) \frac{V_{B C}+V_{D C}}{2 I}\left[\frac{\Omega}{\text { square }}\right]
$$

where $f$ and $Q$ are the Van der Pauw symmetry and correction factors respectively. Q is given by conditions in equation (6).

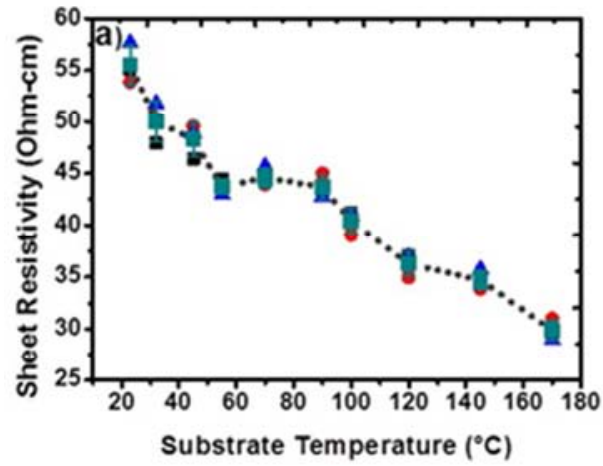

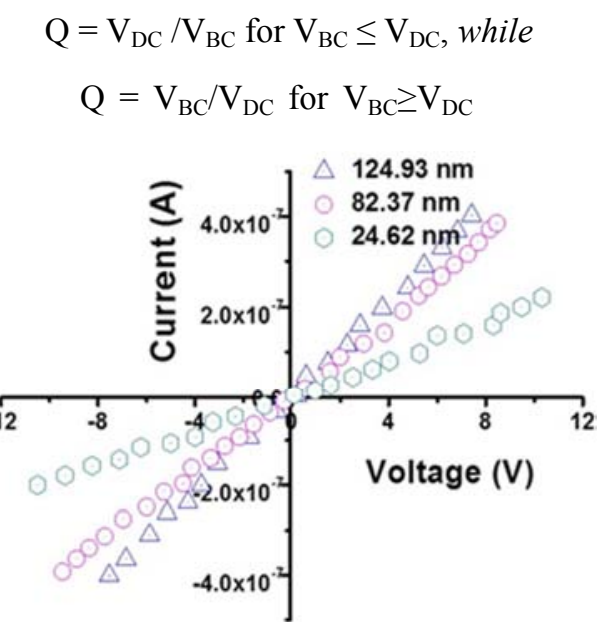

Figure 4. A graph of $\mathrm{I}-\mathrm{V}$ characteristics of $\mathrm{Cu}_{2} \mathrm{O}$ thin films of different thicknesses achieved by varying the deposition time suggesting a more ordered microstructures in thick films as compared to thinner ones.

$\mathrm{f}$ is a function of $\mathrm{Q}$ which is valid for $\mathrm{Q}<10$ and it is expressed in the form:

$$
f=1-0.34657\left(\frac{Q-1}{Q+1}\right)^{2}-0.09236\left(\frac{Q-1}{Q+1}\right)^{4}+\ldots
$$

Equation (7) is obtained by performing cosh expansion of Equation (8) in order to express the symmetry factor, $\mathrm{f}$ in terms of the correction factor, $\mathrm{Q}$.

$$
\frac{Q-1}{Q+1}=\frac{f}{0.693} \operatorname{arcosh}\left(\frac{e^{0.693 / f}}{2}\right)
$$

Taking only the first two terms of equation (7) since the proceeding terms are negligible, equation (9) is achieved.

$$
f=1-\frac{\ln 2}{2}\left(\frac{Q-1}{Q+1}\right)^{2}
$$

The sheet resistivity $\left(\rho_{\mathrm{s}}\right)$ can be expressed in terms of the film thickness, $t$ in nanometres and the sheet resistance, $R_{s}$ as depicted in equation (10).

$$
\rho_{\mathrm{s}}=\mathrm{R}_{\mathrm{s}} 10^{2} \mathrm{t} \Omega \mathrm{cm}
$$

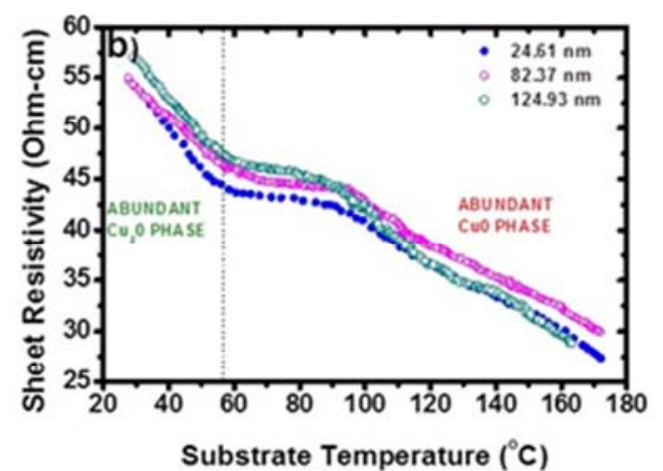

Figure 5. A graph of sheet resistivity verses substrate temperature (a) and optical band gap $E_{g}$ verses substrate temperatures (b). 
This equation was programmed in LabVIEW software that after collecting the sourced current (I) and the voltage (V) from the Source Meter, and the film thickness from the profilometer computed the sheet resistivity and displayed the result on the computer screen. When sheet resistivity of the thin film was plotted as a function of the substrate temperature, the graph in Figure 5 (a) was obtained.

As depicted by the graph, it was observed that the resistivity decreased with increasing substrate temperature and this confirmed the semiconducting nature of $\mathrm{Cu}_{2} \mathrm{O}$. It is seen that the surface sheet resistivity at room temperature of $23^{\circ} \mathrm{C}$ was ca. $55.08 \Omega \mathrm{cm}$ and as the sample temperature was increased, the sheet resistivity dropped to ca. $29.67 \Omega \mathrm{cm}$ at a temperature of $170^{\circ} \mathrm{C}$. The decrease in resistivity with substrate temperature can be attributed to improved crystallinity of the films for all the three different thicknesses [28-30]. From equation (10), sheet resistivity, $\rho_{\mathrm{s}}=\mathrm{R}_{\mathrm{s}} 10^{2} \mathrm{t} \Omega \mathrm{cm}$. This suggests that the sheet resistivity increases nearly linearly with the film thickness as depicted in Figure 5(b). The decrease in the electrical resistivity may also be considered to be caused by desorption of oxygen from the film surface.

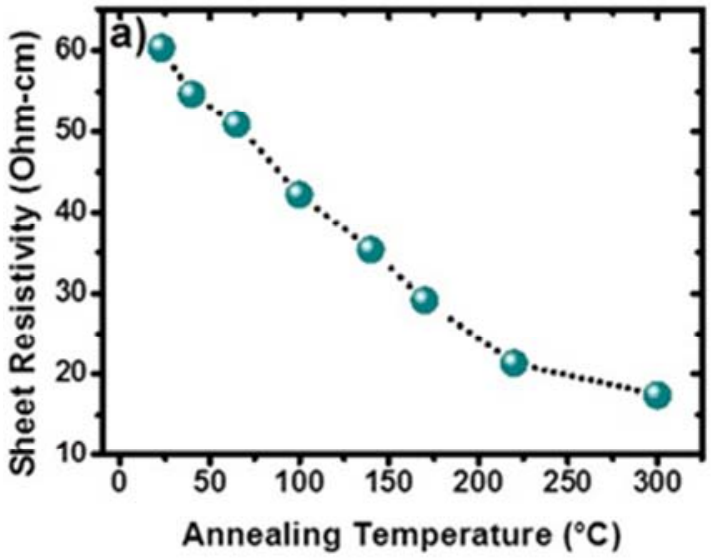

\subsection{Post-Deposition Treatment (Annealing)}

Figure 6(a) shows a plot of sheet resistivity of $\mathrm{Cu}_{2} \mathrm{O}$ thin film as a function of the annealing temperatures indicating a drop. On the other hand, Figure 6(b) shows diffractograms collected from the as deposited $\mathrm{Cu}_{2} \mathrm{O}$ thin film sample and after annealing at $300^{\circ} \mathrm{C}$ in a vacuum for 12 hours. The X-Ray diffraction profiles of non annealed samples shows weak (110) and (111) reflection peaks suggesting poorly crystallized films dominated with $\mathrm{Cu}_{2} \mathrm{O}$ phase. On annealing, there is strong (111) reflection and the emergence of (200) reflection indicating the polycrystalline nature of the film. Stronger (220) and (311) peaks were also observed. The increase in intensity of the reflection peaks also suggest improved crystallinity on annealing. The annealing process could have led to healing of defects created during the oxidation process thereby lowering the resistivity of $\mathrm{Cu}_{2} \mathrm{O}$. Annealing could have also supported the conversion of the polycrystalline $\mathrm{Cu}_{2} \mathrm{O}$ obtained after the oxidation process to single or nearly single crystal phase of tenorite structure with composition of $\mathrm{CuO}$. [1, 2, 30-33].

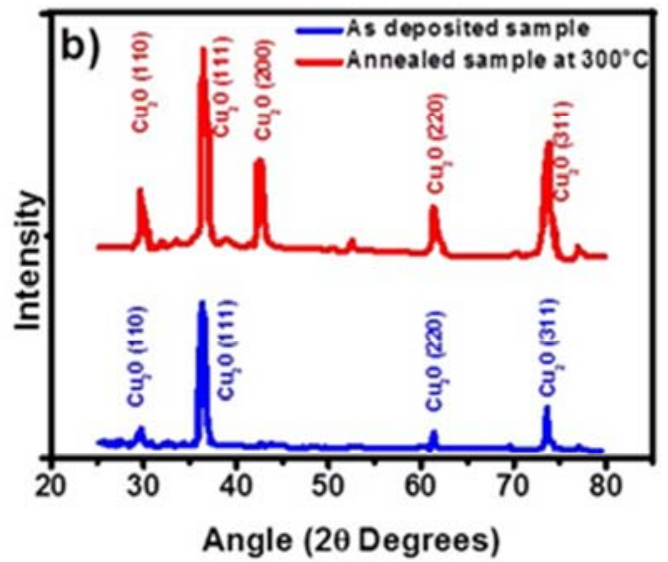

Figure 6. A plot of sheet resistivity verses annealing temperature (a) and the corresponding diffractograms (b) collected from the as deposited Cu $\mathrm{O}_{2}$ thin film sample and after annealing at $300^{\circ} \mathrm{C}$ in a vacuum for 12 hours.

\section{Conclusion}

The method of film preparation has been found to be the main factor affecting the optical and electrical properties of thin films as it determines the film crystal perfections, structural and electronic defect concentration, dislocation density, void or porosity content, grain morphology, chemical composition and stoichiometry and electron trap densities. Further, the post-deposition treatment (annealing) has also been found to determine both the optical and the electrical properties of the thin films.

\section{Acknowledgements}

I would like to extend my sincere gratitude to my advisors Prof. John Okumu, Dr. Patrick Mwangi Karimi and Dr. Walter Njoroge of Physics department, Kenyatta University for their discussions and support. I further appreciate the National
Council of Science, Technology and Innovation (NACOSTI), Kenya for their funding.

\section{References}

[1] H. Soonmin, International Journal of Recent Scientific Research, 7, 6, 11914-11918, 2016.

[2] H Hashim, IOP Conf. Ser.: Mater. Sci. Eng. 99 012032, 2015.

[3] L. Wan, Z. Wang, Z. Yang, W. Luo, Z. Li, Z. Zou, Journal of Crystal Growth 312, 21, 2010.

[4] I. Ezenwa, Research Journal of Recent Sciences, 1, 2012.

[5] W. Septina, S. Ikeda, M. A. Khan Electrochimica Acta, 56, 13, 2011.

[6] C. A. N. Fernando, L. A. A. D. Silva, R. M. Mehra, K. Takahashi Semiconductor Science and Technology 26, 2001, 433. 
[7] H.-C. Chu, C.-L. Lai, C.-Y. Wang, Thin solid films, 517, 15, 2009.

[8] Z. Z. Chen, E. W. Shi, Y. Q. Zheng, W. J. Li, B. Xiao, J. Y. Zhuang Journal of Crystal Growth, 249,294, 2003.

[9] A. Ogwu, T. Darma, E. Bouquerel, Journal of Achievements in Material and Manufacturing Engineering, 24, 1, 2007.

[10] X. Mathew, N. R. Mathews and P. Sebastian, Journal of Solar Energy Materials and Solar Cells, 70, 3, 2001.

[11] A. Reddy, G. V. Rao, S. Uthanna, P. S. Reddy, Physica B, 3, 9, 2005.

[12] L. F. Gou, C. J. Murphy, Nanoletters, 3, 231, 2003.

[13] R. A. Sivasankar, V. R. G., S. Uthanna, and R. P. Sreedhara, Applied Surface Science, 253, 12, 2007.

[14] K. Akimoto, S. Ishizuka, M. Yanagita, Y. Nawa, G. Paul, T. Sakurai, Solar Energy, 80, 715, 2006.

[15] B. Balamurugan, B. Mehta, Thin solid films, 396, 1, 2001.

[16] R. A. Sivasankar, P. Hyung-Ho, R. Sahadeva, K. U. Sarmab, R. Sreedhara, Materials Chemistry and Physics, 110, 5, 2008.

[17] K. Khan, Y. Leung, J. Kos, Renewable Energy, 11, 293, 1997.

[18] R. J. Iwanowski, D. Trivich Solar Cel ls, 13, 253, 2001.

[19] C. Fernando, S. Wetthasinghe, Journal of Solar Energy Materials and Solar Cells, 63, 299, 2000.

[20] S. C. Ray, Journal of Solar Energy Materials and Solar Cells, $68,307,2000$.

[21] T. Mahalingam, J. Chitra, S. Rajendran, M. Jayachandran, J. Mary, Journal of Crystal Growth, 216, 304, 2000.
[22] K. Mizuno, M. K. Izaki, T. Murase, M. Shinagawa, M. Chigane, A. Inaba, A. Tasaka, Y. Awakura, Journal of Electrochemical Society, 152, C179, 2005.

[23] S. Cho. Metals and Materials International, 19, 1327-1331, 2013.

[24] J. Goodenough, J.-S. Zhou, J. Chan, Physical Review, B 47 9, 1993.

[25] S. C. Ray, Solar Energy Material \& Solar Cells 68 307-312, 2001.

[26] W. P. T. Young Sung Kim, Applied Surface Science 253 4911-4916, 2007.

[27] I. Ezenwa, Research Journal of Recent Sciences, 1, 1, 46- 50, 2012.

[28] S. A. Maki, O. A. Mahmoud, Journal of Multidisciplinary Engineering Science Studies, 3, 4, 2017.

[29] Y. Wang, P. Miska, D. Pilloud, D. Horwat, F. Mücklich and J. F. Pierson, Journal of Applied Physics 115, 073505, 2014.

[30] D. S. Murali, S. Kumar, R. J. Choudhary, A. D. Wadikar, M. K. Jain, and A. Subrahmanyam, AIP Advances, 5, 047143, 2015.

[31] M. Onimisi, International Journal of Physical Sciences, 3, 8, 2008.

[32] P. Mitra, Journal of Physical Sciences, 14, 235-240, 2010.

[33] N. Serin, T. Serin, Ş. Horzum and Y. Çelik, Semiconductor Science and Technology, 20, 5, 2005. 